\title{
Investigating the Human Computer Interaction Problems with Automated Teller Machine (ATM) Navigation Menus
}

\author{
Kevin Curran \& David King \\ Intelligent Systems Research Centre \\ Faculty of Engineering \\ University of Ulster \\ Northern Ireland, UK \\ E-mail:kj.curran@ulster.ac.uk
}

\begin{abstract}
The Automated Teller Machine has become an integral part of our society. Using the ATM however can often be a frustrating experience. How often have some of us experienced the people in the queue in front of you reinserting their card for another transaction. Why does this happen? Is there a design flaw in the user interface? It seems that many ATM navigation menus are not as intuitive or as efficient as they could be. This paper examines a variety of UK Bank ATM navigation menus and proposes a best of breed ATM menu.
\end{abstract}

Keywords: Human computer interaction, HCI, ATM interface design, Computer applications

\section{Introduction}

ATM stands for; Automated Teller Machine. It is also referred to as a cash machine, a cash dispenser and 'the hole in the wall' among other names. The ATM is an electronic computerized telecommunications device that allows financial institutions (e.g. bank or building society) customers to directly use a secure method of communication to access their bank accounts. The ATM is a self-service banking terminal that accepts deposits and dispenses cash. Most ATM's also let users carry out other banking transactions (e.g. check balance). ATM's are activated by inserting a bank card (cash or credit card) into the card reader slot. The card will contain the customers account number and PIN (Personal Identification Number) on the cards magnetic stripe. When a customer is trying to withdraw cash for example, the ATM calls up the banks computers to verify the balance, dispenses the cash and then transmits a completed transaction notice.

The idea for an ATM originally was to simply replace or reduce the workload of a bank teller (i.e. the person in the bank who gives out money to customers). The ATM would help reduce banks overheads as wages would be decreased. As for who created the first ATM or where it was first used is a topic of much debate. Basically what answer you get when the question 'who invented the ATM?' is asked depends on who you ask. Miller (2006) presents the facts as he knows it about the history and invention of the ATM. The notion of having a bank machine which automatically dispensed cash to customers came about in the 1930's. A Turkish born inventor working in America called George Simijan started building an earlier and not-so-successful version of an ATM in the late 1930's. He registered the related patents. Simijan came up with the idea of a 'hole-in-the-wall' machine which would allow customers to make financial transactions. However, at the time this idea was well ahead of its time and was met with great doubt. Simijan registered 20 patents related to the device and persuaded an American bank to trial it. However, after 6 months the bank reported little demand in the service and it was withdrawn. It was not until the 1960's that the idea of the ATM was looked at again. John Shepherd-Barron, an inventor from the UK, had an idea in the 1960's for a 24/7 cash dispenser. At the time Shepherd-Barron was the managing director of a company called De La Rue Instruments which today still manufactures cash dispensers. People who believe John Shepherd-Barron invented the ATM argue that the worlds first ATM was installed outside a north London branch of Barclays in 1967.

In 1965 a Scottish man called James Goodfellow was given a project to develop an automatic cash dispenser. Goodfellow was a development engineer with a UK company called Smiths Industries Ltd. He designed a system which accepted a machine readable encrypted card and had a numerical keypad used to enter a PIN. This design is covered in patents in both the UK and USA among other countries. This patent still describes the basic ATM function 40 years later (i.e. the design was patented in 1966). Goodfellow's machines were marketed by Chubb Ltd and installed throughout the UK during the late 1960's and early 1970's. Don Wetzel, then the Vice President of Product Planning of the American Corporation Docutel, claims he applied for a patent on an ATM in 1968. In fact some people believe Wetzel to be the inventor of the ATM. However, an ATM design patented in 1973, stating the Docutel Corporation as the assignee, states John D White as the inventor. White claims he started working on ATM system in 1968 and he 
installed the first ATM in 1973. This machine was called the 'Credit Card Automatic Currency Dispenser'. Evidence suggests it was White who received the patent and not Wetzel. There is also a statement in the patent which supports the idea of the modern ATM - "Both the original code and the updated code are scrambled in accordance with a changing key". This is basically what happens today. ATM's have security keys programmed into them. The code changes and is scrambled to prevent access to credit and ATM card numbers between the ATM, the bank and the network processor. It is clear that the topic of ATM invention is quite a controversial one. However, the combined effort of all the inventors surely has helped create today's ATM. Anyone who worked on ATM design from the 1930's until today has contributed something to the modern ATM designs. The purpose of this research is to investigate existing ATM design and to design a 'best of breed' ATM user interface design.

\section{Interacting with ATMs}

Although ATM's provide an extremely useful service to banks customers, at times they can be very frustrating to use and therefore there is a lot of room for improvement in the interface design. The interface enables communication between the user and the machine. Therefore good user interface design is imperative for high usability levels. Often there are problems or inconveniences experienced when using an ATM. Some of these problems include:

- Waiting in the queue to use the ATM. If users ahead of you in the queue experience difficulties in using the machine, this will increase the time waiting in the queue.

- Inability to see the ATM screen well. This depends on the location of the ATM in relation to the position of the sun. At times it can be difficult to view the contents of the ATM menu.

- Wrongly inserting the ATM card. This problem is more common with new ATM users who are not familiar with their new card and the ATM.

- Getting the required amount of money. Some ATM's may not offer the user the required amount of money they want on the initial cash withdrawal screen. The user will then have to use a few more key strokes to select the required amount (e.g. to withdraw $£ 50$ the user might have to select the 'other amounts' option then type in '50' using the keypad and then press 'enter').

- Understanding how to perform operations. Some ATM users find the instructions on how to perform operations quite difficult to understand.

- Often the ATM card is returned to the user while further operations are required (e.g. the card is returned once the user requests a sum of cash. However the user may want to do further transactions; such as check balance or top-up a mobile phone). This will lead to the customer having to re-insert their ATM card, further increasing their time spent at the ATM.

- On some ATM machines the menu options are not aligned with their corresponding menu key. An example of this is illustrated in Figure 1.

Although the sums of money $£ 10$ to $£ 100$ are not aligned with the related keys, most users will be able to determine what keys are to be used to select the required sum of money. However, if a user wanted to select the 'Other Amounts' option; what button is to be pressed? There is obvious reason for confusion here. It is evident that problems exist with the use of ATM's. Some of these problems are unavoidable (e.g. an ATM running out of money) but solutions exist for others. This research paper focuses on the user interface design problems. ATM navigation menus could be improved considerably to make ATM's more usable.

As technology increases the ATM interface should evolve to take advantage of the new technological innovations. This has happened to a certain extent over the years. However, it is clear that most of today's ATM interfaces do not have the desired high level of usability they should. The modern ATM should be flexible, expressive and easier to use. As mentioned earlier ATM's were introduced in the UK in the late 60's and early 70's. ATM's can now be found in shops, hotels and airports among other places. There was a major design problem when ATM's were first introduced (Dix et al., 1998). During a transaction the ATM dispensed cash to the customer before returning the customers card. This resulted in customers not collecting their card from the ATM. This design problem has now been rectified. The customers' card is returned before cash is dispensed. There have been improvements in the usability of ATM's over the years but there is still a lot of room for improvement. The modern ATM is much more than a simple cash dispenser. Standard UK ATM's offer relatively basic services including cash withdrawals; balance checks and the ability to top-up pay-as-you-go mobile phones. ATM's in different countries (such as USA and Japan) tend to offer advanced services which include cash deposits, cheque deposits, paying bills, purchasing tickets (e.g. train, concert) and purchasing stamps.

The design of an ATM should not only include its inherent usability but also its perceived usability'. This is just one version of possible problems encountered when using (or trying to use an ATM). It reinforces the problems that exist with ATM use. Another typical problem, which was already mentioned earlier, is when an ATM returns the customers 
card prematurely i.e. the user still has additional transactions to make. This problematic process is as follows (say the customer wants to with draw cash and then check their balance):

- Insert card

- Enter PIN

- Choose transaction option (Withdraw cash)

- Select/Enter amount of cash to be withdrawn

- Receipt? (yes/no)

- Card ejected from ATM

- Take cash

- Re-insert card

- Enter PIN

- Choose transaction option (Balance Enquiry)

- Return card

This shows how using an ATM can be frustrating. Human computer interface is a term used to describe the interaction between a user and a computer; in other words, the method by which a user tells the computer what to do, and the responses which the computer makes (Heathcote, 2000). (Preece, 1994) also states Human-Computer Interaction (HCI) is about designing computer systems that support people so that they can carry out their activities productively and safely. This can be summarised as 'to develop or improve the safety, utility, effectiveness, efficiency and usability of systems that include computers'. If ATM's were more usable then they would become more effective and efficient machines as users would find them easier to use. This would cause the users to spend less time using the machines and to carry out more efficient transactions. This would be very desirable as it would lessen waiting times in a queue to use an ATM's services. This research paper is concerned with the usability of ATM's; to investigate why existing ATM's user interfaces (navigation menus in particular) have problems and to design a proposed 'best of breed' ATM menu system with excellent usability. Preece (1994) explains usability is concerned with making systems easy to learn and easy to use. Poorly designed computer systems can be extremely annoying to users. This point is particularly relevant. ATM's, at times, can be extremely annoying to use for many reasons which were mentioned earlier. In order to produce computer systems with good usability HCI specialists strive to understand the factors that determine how people operate and make use of the computer technology effectively; develop tools and techniques to help designers ensure that computers systems are suitable for the activities for which people will use them and achieve efficient, effective and safe interaction both in terms of individual human-computer interaction and group interactions.

The last point is relevant for ATM design as users want their banking interactions to be as quick as possible. However, using an ATM's services is very personal (especially with the development of ATM crime) so the group interactions can be ignored in this case. A good interface design can help to ensure that users carry out task when the using the system:

- Safely - this is important for safety-critical software systems; such as software for a jumbo jet for example.

- Effectively - the user get what they want from the system e.g. if an ATM user requests $£ 100$ cash, the user should get this and not $£ 50$.

- Efficiently - this is the main point concerned with this research paper. If the ATM menu's were improved this would make ATM use more efficient. For example users don't want to spend 5 minutes trying to find the correct way to insert their cash card and type their PIN and the amount of cash they want and then eventually leave without remembering to extract their cash card.

- Enjoyably - systems should be attractive and inviting. Generally if a system is effective and efficient to use, it should also be enjoyable to use as a consequence. However additional effort could be made in ATM interface design to make ATM's more enjoyable to use such as making the screens and menus more colourful and have images for example. A lot of ATM's still just have a black background screen with illuminated text, which is quite dull.

Well designed systems can improve systems significantly. They can improve the output of employees, improve the quality of life and make the world a safer and enjoyable place. An ATM is a service a bank offers to its customers. There are two factors which contribute to the usage of a particular ATM. These are location and the usability of the ATM. Obviously location is the major factor. If an ATM is conveniently located then it will be used a lot. If an ATM is easy to use then this will encourage customers to use the ATM. Many people may have preferences over other ATM's and if they had the choice would use their preferred ATM all the time. All in all, the greater usage a banks ATM 
receives, the more potential there is for the bank to make profit. This is why a bank or building society should not under-estimate the importance of good ATM interface design.

Preece (1994) states that 'the best user interface design guidelines are guidelines in a true sense: high level and widely applicable directly principles'. The following principles can be applied widely:

- Know the user - This can often be difficult to achieve, especially when a diverse population of users has to be accommodated or when the users can only be anticipated in the most general terms. This is particularly true for ATM user interface design as this system has a wide range of users from teenagers to pensioners.

- Reduce Cognitive Load - This concerns designing so that users do not have to remember large amounts of detail. Again this is very relevant for ATM user interface deign. The ATM system should be easy to use and users should remember how to understand how to use the system.

- Engineer for errors - a system should be designed to accommodate inevitable user error. If the user makes an error while using the system the system should be able to recover. Engineering for errors includes taking forcing actions to try and prevent users from making errors initially, providing good error messages, and using reversible actions to apply users to correct their own errors.

- Maintain consistency and clarity - Consistency emerges from standard operations and representations and from using appropriate metaphors that help to build and maintain a user's mental model of a system. For example the 'desktop' in a PC is an appropriate metaphor of a work desktop in an office. ATM user's interfaces generally use consistent language e.g. withdraw cash, PIN services etc. However, different banks offer different ATM user interfaces. It would be ideal if there was a universal ATM user interface design, or at least a standard design in each country.

A number of studies have already been carried out regarding ATM's. Most of these studies however have focused on ATM use in relation to the age of users and user disabilities (such as blindness). Adams and Thieben (1991), Mead et al. (1996), Rogers et al. (1997) and Rogers and Fisk (1997) concentrate on ATM use in relation to the age group of the users. Mankze et al. (1998) focuses on ATM usability by the blind while Hone et al. (1998) focuses on modes of control for ATM's including voice control. Rogers et al. (1994) say that they have been informed by banking staff that training is not necessary for ATM's because they are inherently user friendly. This statement however is often not true as many people find ATM's difficult to use, never mind the elderly users and users who are disabled in some way (for example blind). There has also being significant research done on ATM usability and user behaviour. (Hatta and Liyama (1991), El Haddad and Almahmeed (1992), Burford and Baber (1993), Rugimbana and Iversen (1994), Mead et al. (1996), Pepermans et al. (1996), Rogers et al. (1996, 1997), Rogers and Fisk (1997) but none propose a best of breed system. This research is concerned with usability of ATM's. Each ATM investigated (one from each bank e.g. Bank of Ireland, First Trust etc) is evaluated and measured by efficiency (transaction times). This is done using 'mock-up' ATM prototypes which are direct replicas of the Bank's ATM menu designs.

\section{ATM System Design}

Here we look at the design of the proposed ATM 'best of breed' menu system in relation to the potential users who could use the system. Figure 2 shows a sequence diagram for a complete operational ATM system. The proposed 'best of breed' ATM system does not need to worry about factors such as, insufficient cash or invalid card, as it only concentrates on simulating an ATM navigation menu system.

Existing ATMs menus will need to be mapped out. This is done by visiting each ATM and using the ATM, while at the same time drawing out the menu systems. The Bank/Building Society ATMs which will be visited are First Trust, Ulster Bank, Bank of Ireland, Northern Bank and Nationwide as these appear to be the most commonly used ATMs in the city. To speed up the process of capturing the ATM menus a template was used as illustrated in Figure 3.

Figure 3 represents a standard ATM screen and selection keys enabling the ATM menus to be drawn out quickly and more importantly accurately. It is crucial that each ATM menu system is mapped out accurately as these correspond exactly to the implemented version of the menu systems on the PC. The aim of transferring the ATM menu systems onto a VB program is to simulate the use of the actual ATM systems. Therefore, the performance of each ATM can be determined. When the real world ATM menu systems were drawn out with the aid of the template illustrated in Figure 3, the menu structures needed to be designed before they could be implemented in VB.NET. Once the menu structures were designed and the different levels determined, this made the implementation stage an easier process. In the diagrams/tree structures (see Figure 4) - each box represents a particular menu screen. Due to lack of space, we only include one menu tree structure for the Bank Of Ireland ATM.

The user can only move onto another menu screen after an input i.e. choosing an option. For example, a typical Bank of Ireland ATM transaction may be: 
- User inserts card as prompted

- $\quad$ User enters 4 digit PIN as prompted

- User opts to withdraw $£ 20$ from menu selection

- $\quad$ The user opts to receive an advance slip when prompted

- $\quad$ The user is asked to take card and wait for cash and receipt.

To measure the transaction performance of the various ATMs, a VB program was created to simulate each ATM's real world menu structure to replicate ATM transactions in the lab. The ATM simulation program is used to test and monitor each of the ATMs performance. The user is presented with a collection of buttons. The user will click on the required button, taking the user to that particular banks ATM simulator.

The ATMs simulation user interface 'shell' remains consistent for each ATM i.e. the main screen, the selection keys and the keypad. This is illustrated in Figure 5. The eight selection keys (either side of the ATM screen) will be used to make user selections from the menu. The 'Insert Card' button will be used to simulate the user inserting the ATM card into the machine. The keypad containing the digits 0-9 and the keys 'Cancel', 'Clear' and 'Enter' is standard for all the various types of ATMs investigated in this research. The button 'Back to Main Menu' is simply to take the user back to the main screen illustrated in Figure 5.

The 'Best of Breed' ATM menu system (called OptiATM which means optimal ATM menu) also uses the standard interface shown in Figure 5. The system is used to run transaction performance tests on the existing ATM menu designs (as well as the 'best-of-breed' OptiATM). When using an ATM the machine often takes time to process data such as 'processing card' and 'contacting bank/building society' etc. The ATM Simulator will not simulate these processing time periods. However, this will not corrupt the transaction performance test results as it will be consistent for all the ATM simulations. As these processing time periods will not be represented by any of the ATM simulations, the transaction performance test results will be accurate as they are all relative. Another important factor to note is as follows; many inconveniences can occur when using an ATM, such as - ATM has run out of cash, user enters PIN incorrectly, error in reading card - to name a few. The ATM Simulator will not simulate these situations. When using the ATM simulator, 'perfect' transactions will be simulated i.e. the ATM reads the users card without error, the user enters the correct PIN and the user has sufficient funds. The ATM Simulator has a welcoming screen allowing the user to select which ATM to simulate. This is illustrated in Figure 6. Each of the Bank logos are buttons. The user simply clicks on a particular button to go to simulate that particular bank. At this stage, all the buttons take the user to all the existing ATM simulations.

Obviously it is not possible to physically insert an ATM card when using the ATM Simulator. Therefore an 'insert card' button has been created to simulate inserting the card into the ATM. Once this button is clicked by the user, the next menu screen appears. This of course, is the screen which prompts the user to enter their PIN (Personal Identification Number). The requirements of the ATM Simulator were simply to simulate the use of an ATM machine. Therefore this is what the ATM Simulator does. When the users enter their PIN, there are no comparison algorithms or checks to confirm that the PIN entered was indeed correct. As mentioned earlier, the ATM Simulator is just a tool to enable transaction performance tests to be conducted on ATM menu designs.

To enter a PIN, the user simply clicks four digits on the keypad shown in Figure 7. The PIN can be any four digit number so long as it ends with the digit ' 1 '. When this number is clicked, a click event is triggered which takes the user to the next screen. However this action only occurs in the Bank of Ireland, Ulster Bank and Northern Bank ATMs. The other two ATM designs (First Trust and Nationwide) require the user to press the 'enter' key to confirm the PIN entered is correct. In this case, the click event is triggered when the 'enter' key is clicked in the ATM Simulator. These two different actions are reflected in the real world ATM designs.

To select an option from the menu, the user simply clicks on the select key adjacent to the menu option displayed on screen. This is the same when using an ATM in real-life, only the user presses the selection key with their finger. An example of a user selection is illustrated in Figure 8. An Ulster Bank ATM user may want to withdraw cash. Therefore, once the user simulates inserting their card and entering their PIN, the user will click on the selection button adjacent to the option 'Withdraw cash'. This will then present the user with different cash withdrawal options.

Each existing ATM has been designed and implemented to reflect the real-life counterparts. Therefore each ATM, as illustrated in the design chapter using the ATM menu tree structures, will have different menus presenting the user with different options. Using the Bank of Ireland ATM, when the user enters their PIN, they are automatically presented with cash withdrawal options as well as some additional options. This is illustrated in figure 9. Using the Ulster Bank ATM to withdraw cash was already illustrated in Figure 8 earlier. Using the Northern Bank ATM system, simulating user's 
options is illustrated in Figure 10. The initial menu shown here is only of course displayed to the user when the insertion of the ATM card and PIN entered is simulated previously.

As you can see from Figure 10, the user has three options when using the Northern Bank ATM i.e. withdraw cash, withdraw cash with a receipt and display or print balance. Figure 11 show the options a user has when using the Nationwide ATM. Once the user enters their ATM card and PIN number, they are presented with the options; request statement, balance enquiry and cash withdrawal. Figure 11 also shows the subsequent corresponding screens.

First Trust also had its own unique menu design and layout. It was essential that each of the ATMs investigated (i.e. Bank of Ireland, Ulster Bank, First Trust, Nationwide and Northern Bank) be implemented correctly. It was essential that each ATM simulation on the PC directly represented the corresponding banks real life ATM menu design and layout to produce accurate and reliable transaction performance test results.

\section{OptiATM}

Over a period of days, we observed customers using the ATMs. The number of users that were seen re-inserting their ATM cards was recorded against the total number of users seen using the ATM.

The data in Figure12 is graphical represented in Figure 13. This data may indicate that Ulster Bank has the higher usability issues while Northern Bank has the least. However, many factors have to be considered when analysing this data. If the ATM observations were carried out again the results could be a lot different. The main factor which will affect these results is:

- The individuals who use the ATM when the observations are made i.e. are the customers novice, intermediate or expert users. These levels of expertise may be determined by the age of the user for example.

The data in Figure 12 and Figure 13 may be described as insignificant for analytical purposes. However, it still provides an insight into the problems of ATM HCI issues. The data collected reinforces the fact that users regularly have to reinsert their ATM cards to carry out further transactions. It was found out that the main reason why bank customers used and ATM was to withdraw money. This may seem obvious but it was important to make this assumption concrete. Out of the 217 ATM users observed (covering all 5 banks), 202 users said that the main reason why they use an ATM is to simply withdraw cash. The remaining 15 ATM users said they mainly used an ATM to check their bank account balance. This data is illustrated in Figure 14. However, these ATM customers also said that they usually follow up this initial transaction with an additional transaction of withdrawing cash.

This data illustrated in Figure 14 will be useful when designing the menu system for the 'Best-of-Breed' ATM system OptiATM i.e. it would be useful to list the most frequently used options first for example. It is also now clear that a reoccurring problem of ATM use is that customers have to reinsert their cards to carry out additional transactions. The reasons customers gave for reinserting their ATM cards are illustrated in Figure 15.

Simply observing existing ATM usage and asking ATM user's questions did not provide enough information to help create the proposed 'Best-of-Breed' OptiATM. As mentioned in an earlier chapter, each ATMs (i.e. Bank of Ireland, Ulster Bank. First Trust, Nationwide, Northern Bank) menu system was mapped out and implemented to create the ATM Simulation program. Each ATM was performance tested by three different users and an average of the times was recorded. The different performance tests were to (1) Withdraw $£ 20$ (i.e. a standard amount presented to customer); (2) Withdraw $£ 20$ with receipt; (3) Withdraw $£ 300$ (i.e. another amount); (4) Withdraw $£ 300$ with receipt; (5) Check Balance on screen; (6) Print Balance and (7) Check balance and then withdraw £20. These performance tests cover the range of functions offered by a standard ATM and give a good indication of each ATMs overall performance. Due to lack of space we simply show in Figure 16, the average transaction performance times when simulating using a Bank of Ireland ATM.

There are a few issues that were highlighted when running the tests using the Bank of Ireland ATM simulator. The Bank of Ireland ATM is the only system which offers the user immediate cash withdrawal options after the customer enters their PIN. This suggests that the Bank of Ireland ATM designers recognise that cash withdrawals is a primary transaction necessity for its customers. This point was illustrated in Figure 14 earlier. We did notice with the Nationwide ATM that the menu options do not remain consistent. When the user is asked for example; 'Would you like a receipt with this transaction?' the 'yes' and 'no' options are the bottom left and bottom right options respectively. These are selected using the selection keys. However, when the user is asked; 'Would you like another service?' the 'yes' and 'no' keys are not placed here. Alternatively they are both placed on the right hand side of the screen. 'Yes' is selected using the second from bottom key on the right hand side, while 'No' is selected using the bottom key on the right hand side. This is an issue as consistency is one of the key factors in designing good, usable interfaces.

We compared each of the ATMs in a series of transaction performance tests carried out in order to highlight which ATMs perform better than others for certain transactions so as to help identify the best and worst features of each ATM. The results feed into the 'Best-Of-Breed' OptiATM as it contains all the optimum features of existing ATMs and none 
of the poorly performing features. Figure 17 shows the average time each ATM took to withdraw $£ 20$. The reason why the withdrawal of $£ 20$ was chosen as a performance test is that it is a standard withdrawal amount offered by all the ATMs and it is a common transaction for ATM customers.

As you can see from Figure 17, the Bank of Ireland ATM has the fastest cash withdrawal time for standard amounts of cash. This is so because once the user enters their PIN, they are automatically given the option to withdraw cash without the need of any additional keystrokes. The Ulster Bank, Nationwide and Northern Bank ATMs are all relatively close in performance times with the Ulster Bank edging it. It is clear that the First Trust ATM has the worst performance. This is due to First Trust giving the user a lot of information and additional prompts. Ideally the 'Best-of-Breed' OptiATM will have the Bank of Irelands fast cash withdrawal feature incorporated into its menu design.

All five ATMs were evaluated and the results used to influence the 'Best-of-Breed' OptiATM. Again, lack of space prevents us detailing all the individual scenarios. By using the performance test results, the OptiATM should include the features from the ATMs which yield the fastest and most efficient results for each transaction. Ideally the 'Best-of-Breed' OptiATM would have all the best features of the banks ATMs for each particular type of transaction; however it may not be possible for all the different transactions. Each of the ATM menus are systems, meaning they are all inter-related and inter-connected. This means that the 'Best-of-Breed' OptiATM is not able to incorporate the best feature of one particular ATM without keeping some of its less efficient features. Compromise is required when designing the 'Best-of-Breed' OptiATM system.

A 'Best-of-Breed' OptiATM should out-perform existing ATMs however, this does not resolve the problem of users having to reinsert their card after making a cash withdrawal. This problem may occur because of the design and layout of the ATM menu system or the ATM user is not given the option of carrying out another transaction after withdrawing cash. The only possible reason why ATMs don't offer the user the option of another transaction after withdrawing cash is the fact that user might simply take their cash and forget about their ATM card, thus leaving it in the ATMs card slot. Doing this would be both inconvenient and a security risk (as people could obtain the users bank card). Therefore the Best-of-Breed' OptiATM should offer the user 'Do you want another transaction?' when withdrawing cash, but at the same time overcome the problem of making sure that user's cannot leave their ATM card behind. There are some ATMs which operate differently from the ones investigated here. High street banks/building societies (such as the existing ATMs investigated) operate in the following way (1) Insert card, (2) User enters PIN and carries out transaction/s required and (3) User takes card.

Portable ATM's or Independent Convenience Cash Dispensers work in a different manner in that (1) User inserts card; (2) Card is read and user is instructed to remove card and (3) User enters PIN and carries out transaction/s required. This enables customers to be offered 'another transaction' after withdrawing cash. Using this method of operation, customers could withdraw cash and then be prompted 'Would you like another transaction?' This way, once the customer takes their cash, it is not possible to forget their card - as they already took it before they began their transaction. However, this creates a security problem on its own. What if the user just takes their cash and walks off without responding to the prompt 'Would you like another transaction?' Could the next user simply use the previous users account and withdraw cash? A fail-safe would be in place to ensure that this could not happen. If the user does not respond within a given time period e.g. 5 seconds for example, the session ends. In fact this fail-safe would be in place whenever a user is using the ATM at any given time.

The OptiATM is designed to be more efficient and easier to use than the existing ATM systems investigated. Figure 18 shows the user options displayed to the user when the PIN is entered. The OptiATM initial menu screen tries to incorporate all the main user options. This inevitably reduces transaction times. The user is always prompted after a transaction asking the question 'Would you like another transaction?' This is also the case when withdrawing cash, eliminating the problem of having to reinsert their card for another transaction. However, for this to work without problems, the user has to remove card (after details are read of course) before carrying out a transaction. To test whether OptiATM is a 'best-of-breed' ATM menu design capable of out-performing existing ATMs, we put it through a series of tests as illustrated in Figure 19.

Figure 19 shows that the OptiATM is just a little slower at withdrawing $£ 20$ than the Bank of Ireland ATM. This is so because the user has to remove their card before beginning their transaction. However, even taking this into consideration, OptiATM still out performs the other four ATMs.

Figure 20 again shows that the OptiATM is just a little slower at completing this transaction. Again this is due to the fact that the user has to remove the ATM card before continuing with the transaction. Therefore this is an acceptable result. The benefits of the added facility allowing the user to carry out another transaction after withdrawing cash, outweighs the fact that the OptiATM is out performed by both Ulster Bank and the Bank of Ireland.

Figure 21 highlights that the OptiATM can withdraw $£ 300$ i.e. other amounts of cash, faster than any of the other ATMs. This is so because the user can enter the required amount of cash on the main option screen. 
Figure 22 demonstrates the OptiATM design yields the fastest time to firstly check balance and then withdraw £20. OptiATM is an improvement on the tested real world ATM systems. In only two of the seven transaction performance tests carried out did the OptiATM not have the fastest transaction time.

Figure 23 illustrates, although the OptiATM design was beaten in (and only slightly) only two tests, it still has an overall better performance than the best performing existing ATM system.

The fact that the OptiATM design has the added facility of eliminating the need to reinsert ATM cards, while at the same time improving overall performance, reinforces that the OptiATM menu design is an improved 'best-of-breed' ATM menu system.

ATM manufacturers have demonstrated several different technologies which as of yet have not gained worldwide acceptance. These include:

- Biometrics for security purposes i.e. the authorization of transactions is based on the scanning of fingerprints, the eye, face etc.

- Ability to print 'items of value' such as traveller's cheques.

- Customer specific advertising on the ATM.

Some of the examples above are potentially the way forward for ATM's. However, Banks and other providers of ATM services have to determine if these advancements are feasible. They have to ask the questions are they financially feasible and how will customers react to the changes. Although the main topic for this research paper is the problems with ATM interface design, there are many issues with the use of ATM's in today's world. The main issue is security. This can be divided into 2 broad categoreies which are physical security of the ATM and transactional security. Early ATM security focused on making ATM's safe from physical attack. ATM's were basically safes with dispenser mechanisms. It has been recorded that thieves have stole entire ATM's and its housing in an attempt to steal its cash. However, modern ATM physical security focuses on denying the use of the cash inside the ATM to thieves. Using a technique such as dye markers dyes the cash and potentially the thieves, making the cash unusable and increasing the chances of the criminals being caught. Sensitive data in ATM transactions are encrypted. However there are always problems with data security. 'Phantom withdrawals' are a major problem with ATM's. This is when money is withdrawn from a customer's account using an ATM without the customer being aware. Neither the bank nor the customer admits liability for the withdrawals. Many fraud experts believe dishonest insiders (i.e. bank workers) are responsible for phantom withdrawals. Card cloning is also another major ATM security problem. It is possible to clone ATM user's cards by installing a magnetic card reading device over the ATM's real card slot. This is able to store information such as the card number. Once the criminal has this, the card can be cloned onto a second card. Then all that is needed is the ATM users PIN. The criminal can gain this by simply observing the user enter the PIN or by placing a video camera near the ATM recording the user's PIN's being entered. Banks are working on measures to try and counteract card cloning. The use of smart cards for ATM's, as they cannot be easily copied by un-authenticated devices is one potential countermeasure. Banks are also attempting to make the outside of their ATM's tamper proof. Stealing customers ATM cards is a low-tech form of fraud. The user's PIN can be observed by 'shoulder surfing' and a second criminal can then physically steal the customers card. Also, there have been cases reported were ATM users have been 'mugged' after using an ATM machine. ATM users are vulnerable as an observing criminal will believe a user will have cash.

\section{Conclusion}

The main objective was to design a 'best-of-breed' ATM menu system. This was achieved in the form of the OptiATM. As demonstrated, the OptiATM menu design, out performs and is a more usable and efficient system than the existing ATMs investigated. The OptiATM system was designed to resolve the problem of users having to reinsert their ATM cards to carry out another transaction and to speed up transaction times. The system could help improve user's basic everyday ATM transactions however the OptiATM system is basic in that the functions and services they offer. Many advanced ATM machines offer an abundance of additional services including cash and cheque deposits, ability to pay bills at terminal, top-up pay as you go mobile phone and purchasing tickets such as train or concert tickets. ATMs have become part of the modern world's infrastructure. We expect ATMs for convenience as much as we expect a good transport service. However, as the services offered grow, the ATM menu designs will become more complicated. This may lead to the systems becoming even more confusing for users and harder to choose. It is recommended that ATM designers consult extensively with ATM users to help them design and create easy-to-use and efficient ATM systems.

\section{References}

Adams, A. S. and Thieben, K. A. (1991), Automatic teller machines and the older population. Applied Ergonomics, 22, $85-90$.

Bennett, S. McRobb, S. Farmer, R. (1999) Object-Oriented Systems Analysis and Design, McGraw-Hill. 
Burford, B. C. and Barber, C. (1993) ,A user-centered evaluation of a simulated adaptive autoteller, in S. A. Roberston (ed.) Contemporary Ergonomics, London, UK: Taylor and Francis Ltd, 117-122.

Dix, A.J. Finlay, J.E. Abowd, G. D. Beale, R. (1998) Human-Computer Interaction Second Edition, Prentice Hall Europe.

El-Haddad, A. B. and Almahmeed, M. A., (1992), ATM banking behaviour in Kuwait: a consumer survey, International Journal of Bank Marketing, 10, 25 - 32.

Hatta, K. and Liyama, Y., (1991), Ergonomic study of automatic teller machine operability. International Journal of Human Computer Interaction, 3, 295-309.

Heathcote, P.M. (2000) A-Level Computing $4^{\text {th }}$ Edition, Payne-Gallway Publishers Ltd.

Miller, A.W, 2006 [Online], Who invented the ATM machine? Automated Teller History, Available at http://www.atmmachine.com/atm-inventor.html [Accessed 20/11/2006].

Hone, K. S., Graham, R., Maguire, M. C., Baber, C. and Johnson, G. I. (1998), Speech technology for automatic teller machines: an investigation of user attitude and performance. Ergonomics, 41, 962-981.

Mankze, J. M., Egan, D. H., Felix, D. and Krueger, H. (1998), What makes an automated teller usable by blind users? Ergonomics, 41, 982-999.

Mead, S., Walker, N. and Cabrera, E. F. (1996), Training older adults to use automatic teller machines. Human Factors, $38,425-433$.

Pepermans, R., Verleye, G. and Van Capellen S. (1996), 'Wallbanking', innovativeness and computer attitudes: 25 - 40 year-old ATM-users on the spot. Journal of Economic Psychology, 17, 731 - 748.

Preece, J. (1994) Human-Computer Interaction, Addison-Wesley Publishing Company.

Pressman, R. (1997) Software Engineering, A Practitioner's Approach $4^{\text {th }}$ Edition, McGraw-Hill.

Rogers, W. A. and Fisk, A. D. (1997), ATM design and training issues. Ergonomics in Design, January 1997, pp. 4 - 9; http://hfes.org/Publications/TOC/EID-93-97.html

Rogers, W. A., Cabrera, E. F., Walker, N., Gilbert, D. K. and Fisk, A. D. (1996), A survey of automatic teller machine usage across the adult lifespan. Human Factors, 38, $156-166$.

Rogers, W. A., Gilbert, D. K. and Cabrera, E. F. (1997), An analysis of automatic teller machine usage by older adults: a structured interview approach. Applied Ergonomics, 28, 173 -180.

Rugimbana, R. and Iversen P. 1994, Perceived attributes of ATMs and their marketing implications. International Journal of Bank Marketing, 12, 30 - 35.

Sommerville, I. (2004) Software Engineering Edition 7, Pearson Education Limited.

The RadioHead, (2005) [Online], The ATM Experience,

Available at http://theradiohead.blogspot.com/2005/02/atm-experience.html [Accessed 25/11/2006].

Van Vlient, H. (2000) Software Engineering, Principles and Practice, $2^{\text {nd }}$ Edition, Wiley \& Sons.

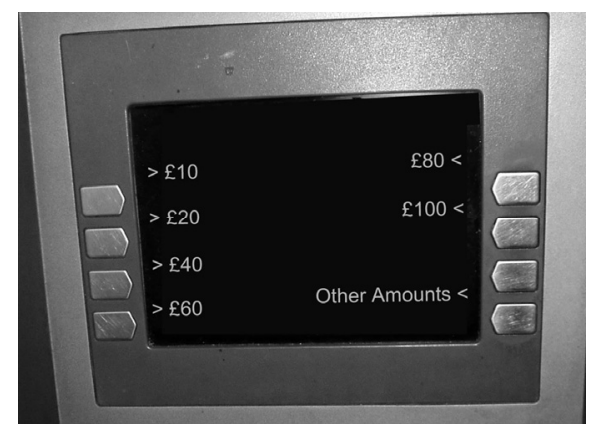

Figure 1. Typical ATM Menu 


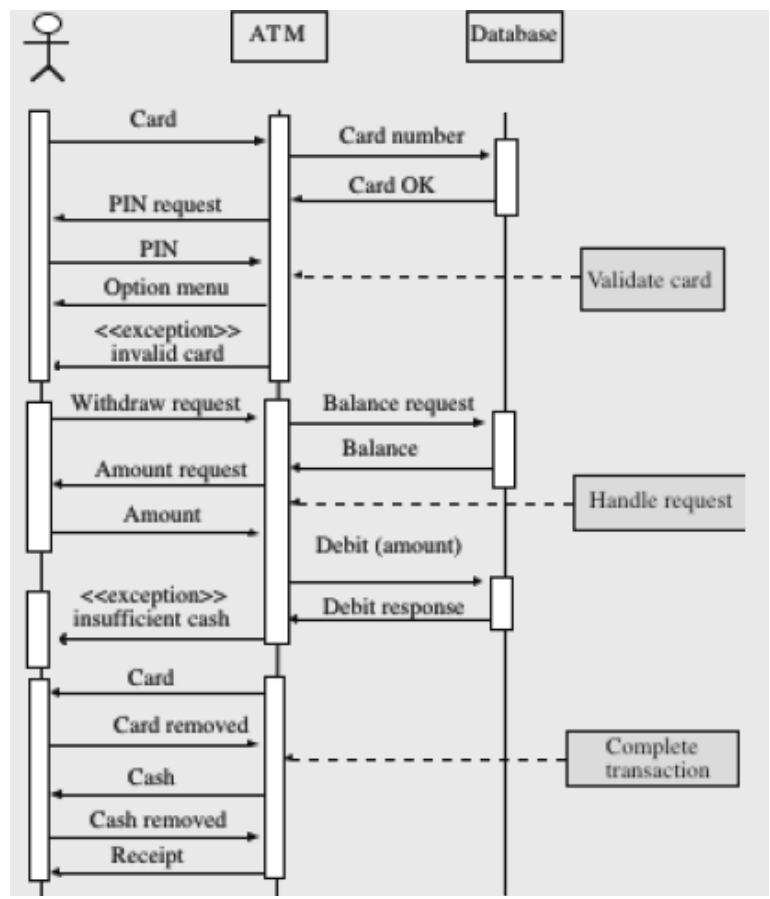

Figure 2. Sequence Diagram of an ATM System (Sommerville, 2004)

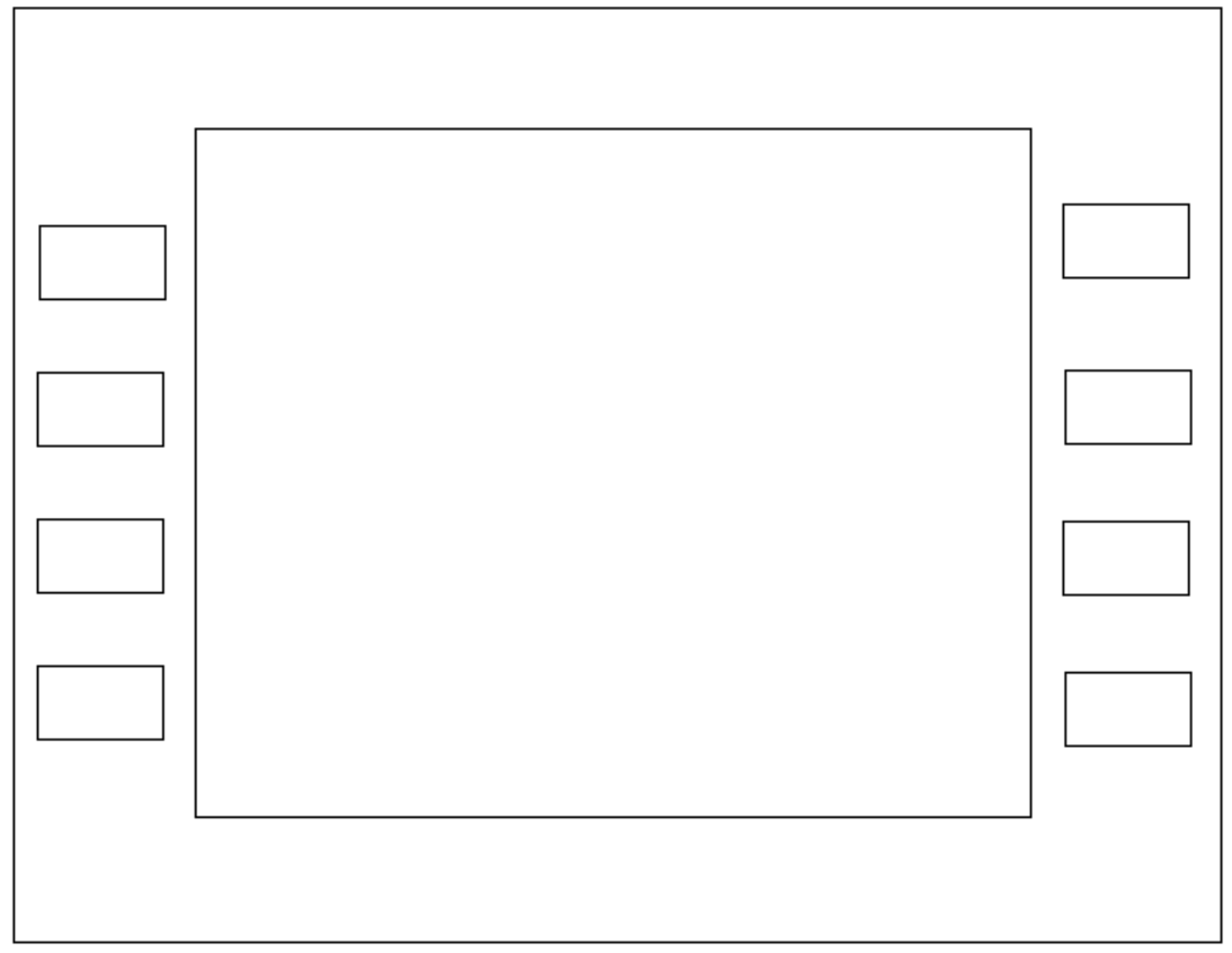

Figure 3. ATM menu screen template 


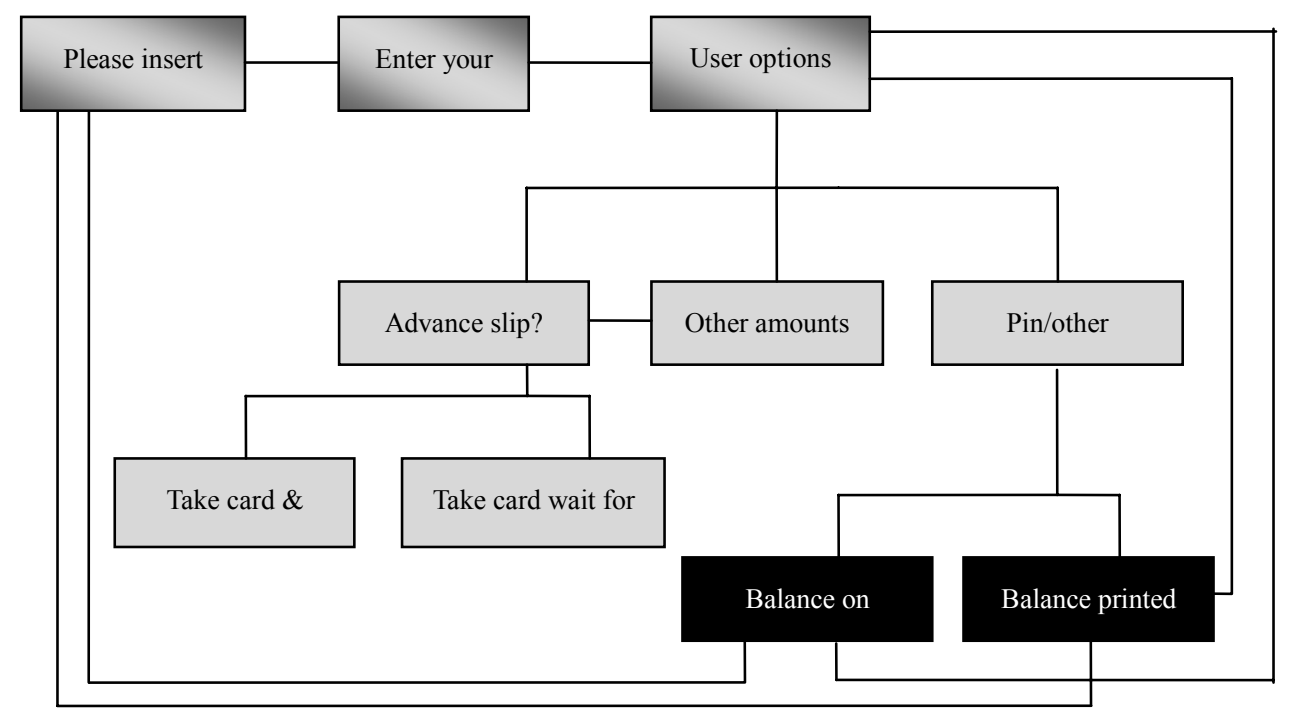

Figure 4. BOI ATM Menu Tree Structure

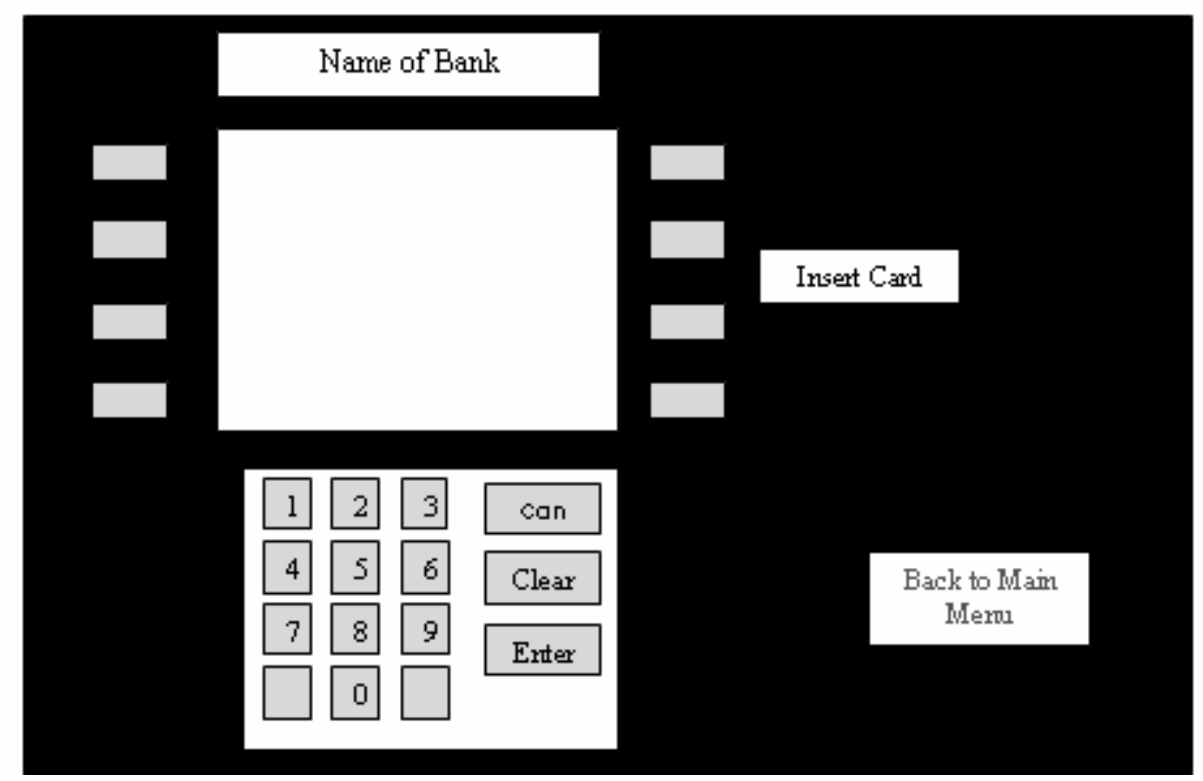

Figure 5. ATM Simulator Interface Design 


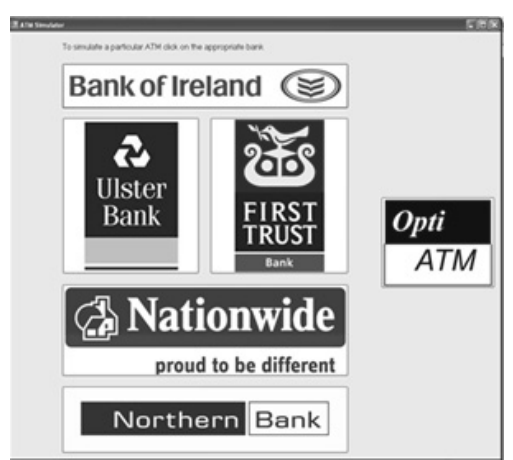

Figure 6. ATM Simulator Main Screen

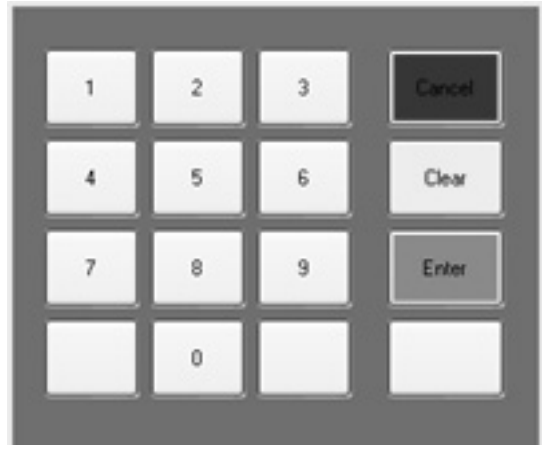

Figure 7. ATM keypad

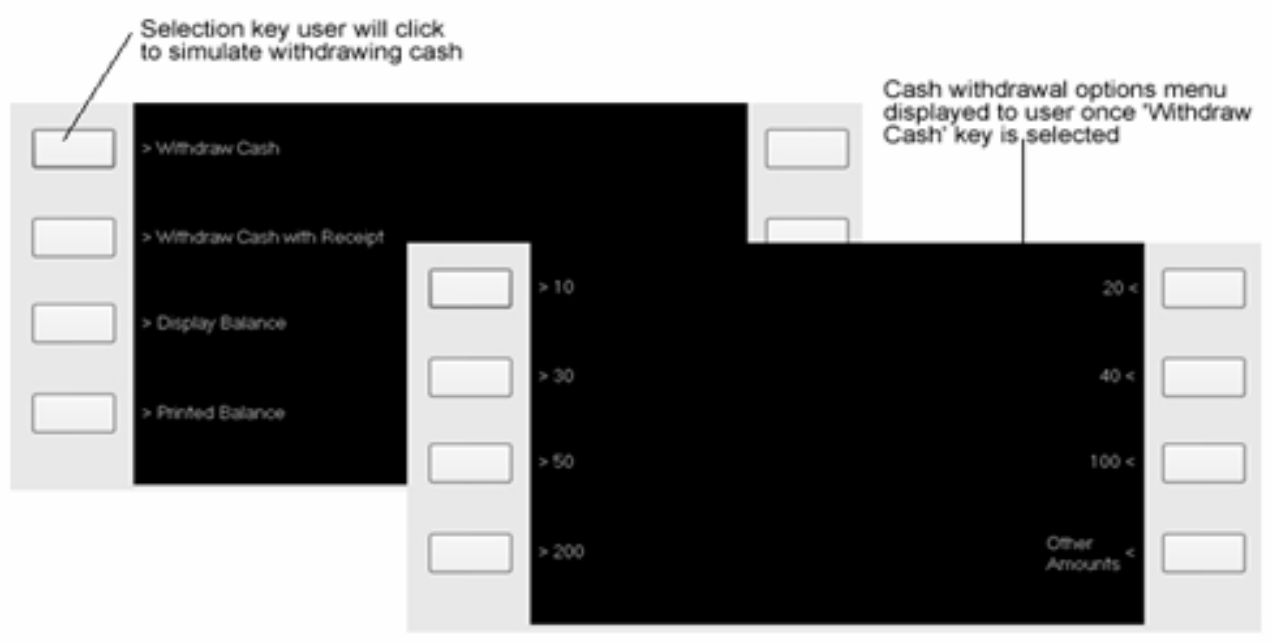

Figure 8. Ulster Bank ATM - Withdraw Cash

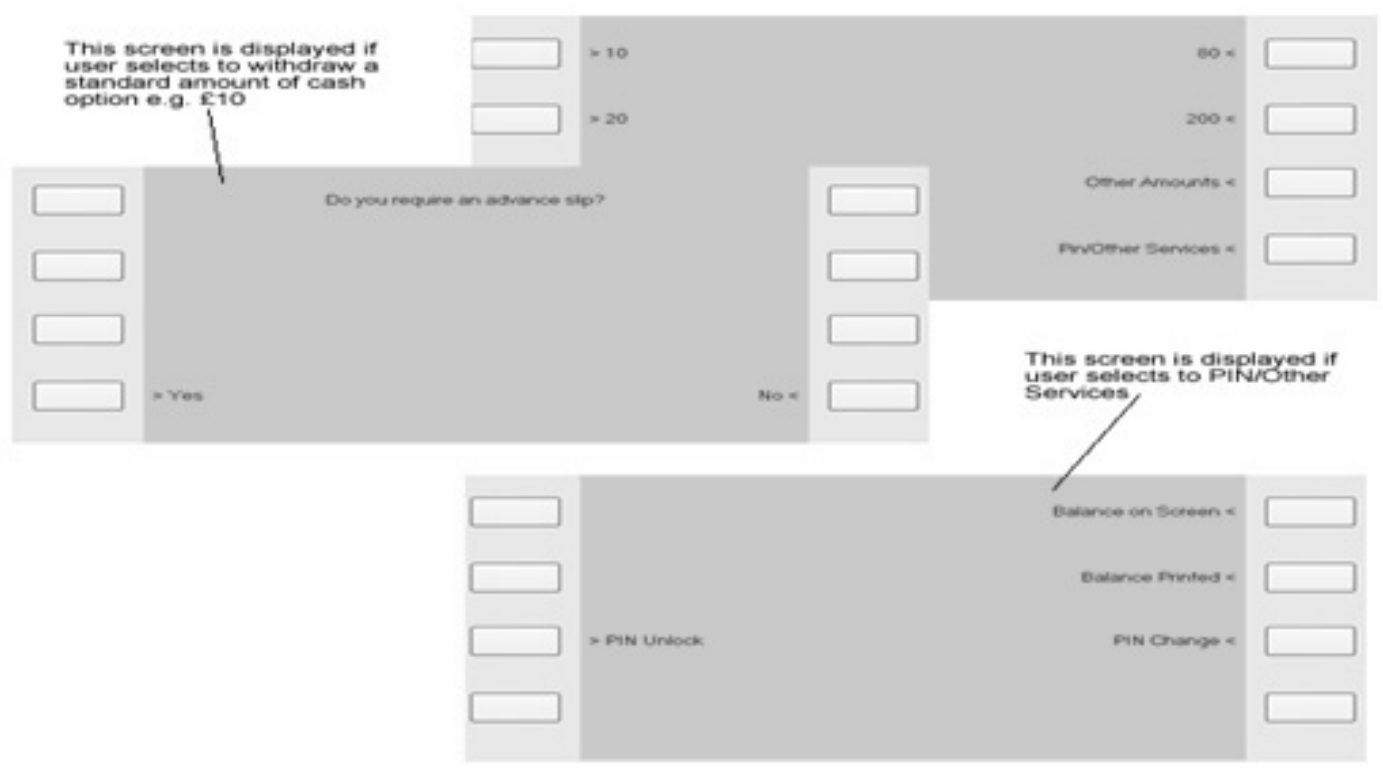

Figure 9. Bank of Ireland ATM User Options 


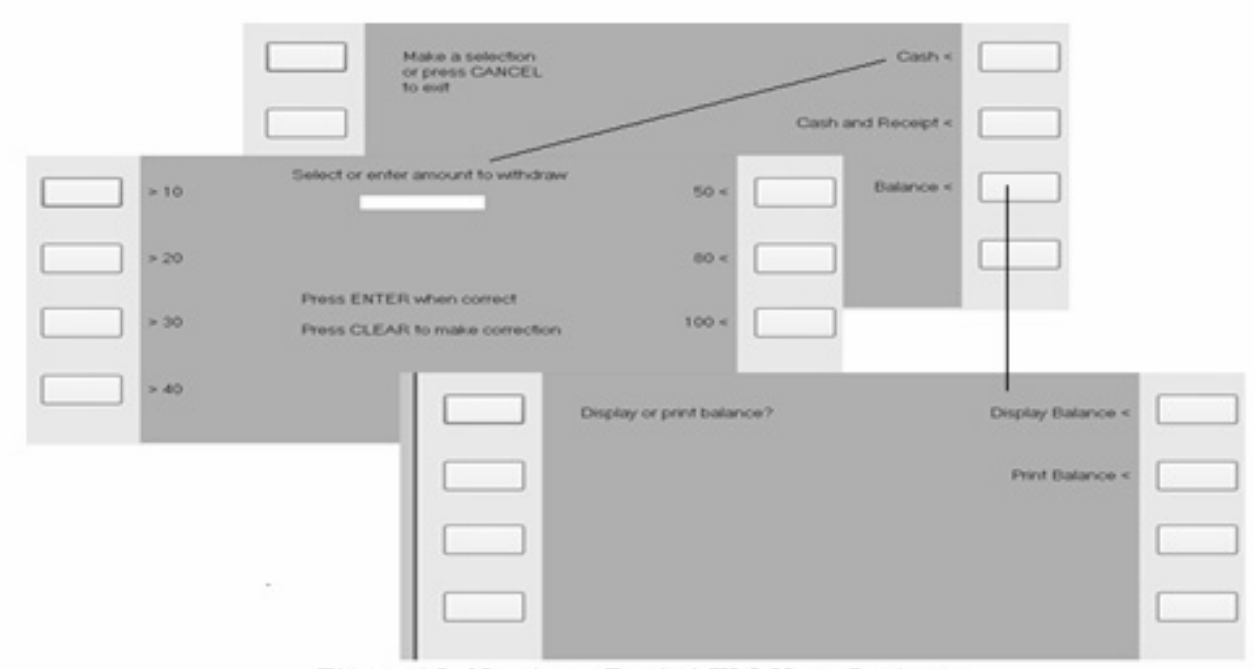

Figure 10. Northern Bank ATM User Options

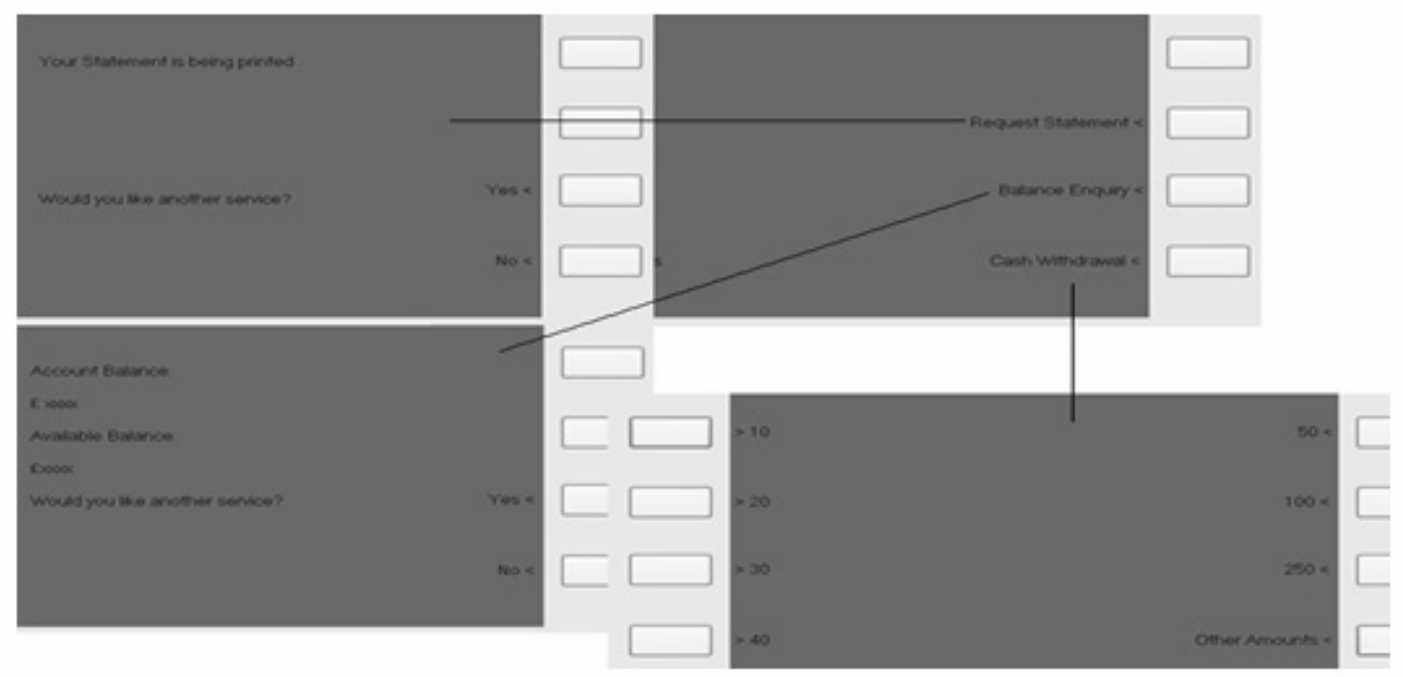

Figure 11. Nationwide ATM User Options

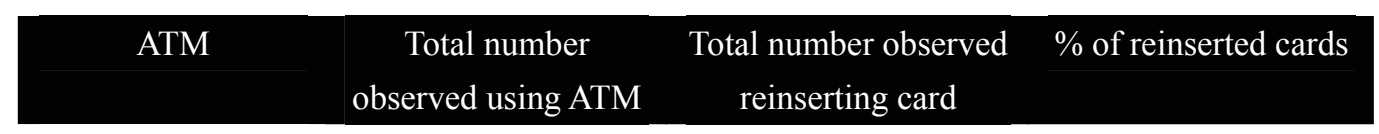

$\begin{array}{cccc}\text { Bank of Ireland } & 41 & 4 & 9.76 \\ \text { Ulster Bank } & 54 & 6 & 11.11 \\ \text { First Trust } & 62 & 2 & 3.23 \\ \text { Nationwide } & 33 & 3 & 9.09 \\ \text { Northern Bank } & 27 & 1 & 3.70\end{array}$

Figure 12. ATM Customers observed reinserting card 


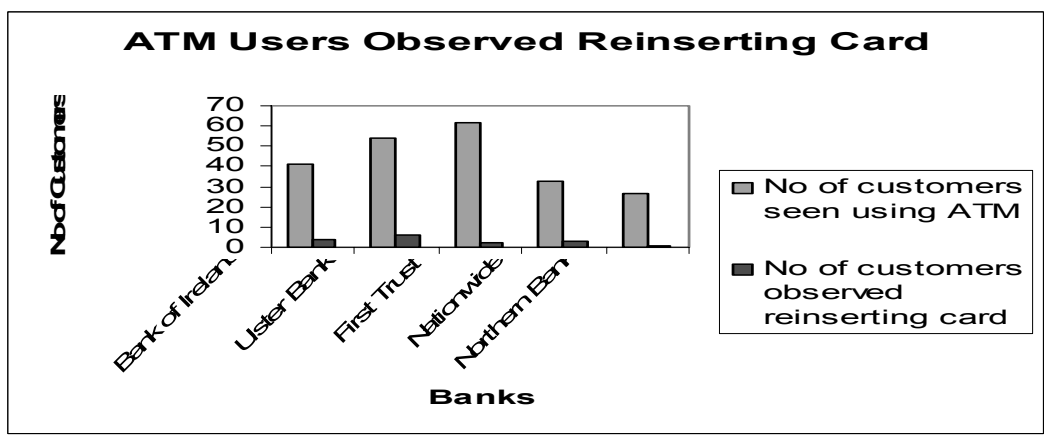

Figure 13. ATM users observed reinserting card

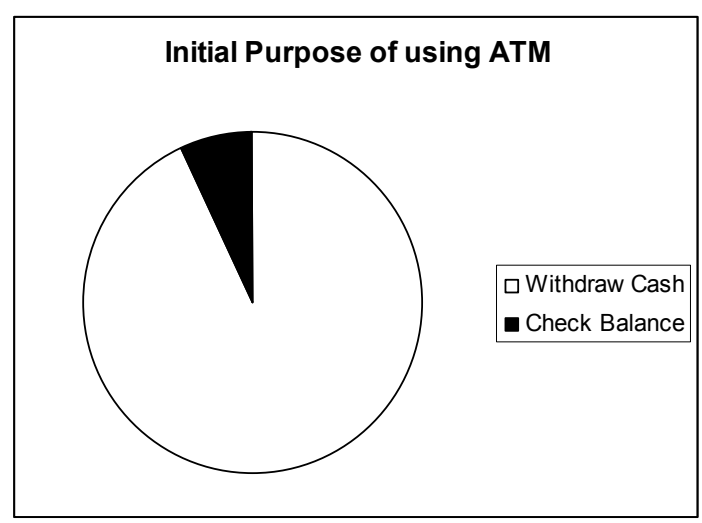

Figure 14. Main purposes of using an ATM

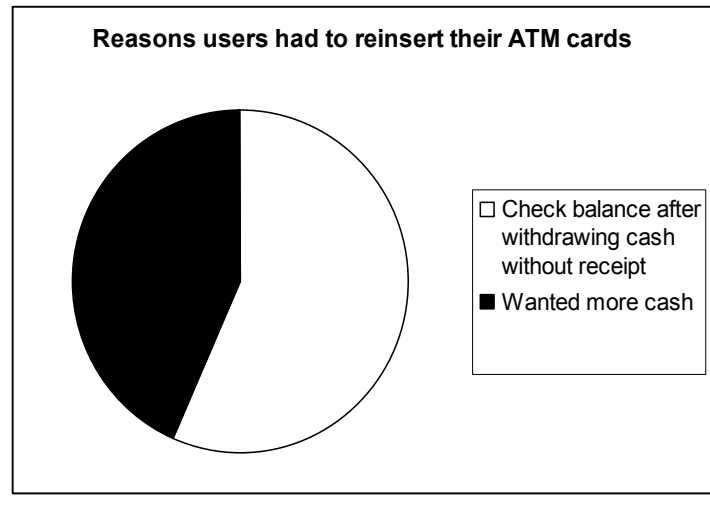

Figure 15. Reasons Users had to reinsert Card 
BOI ATM Transaction Times

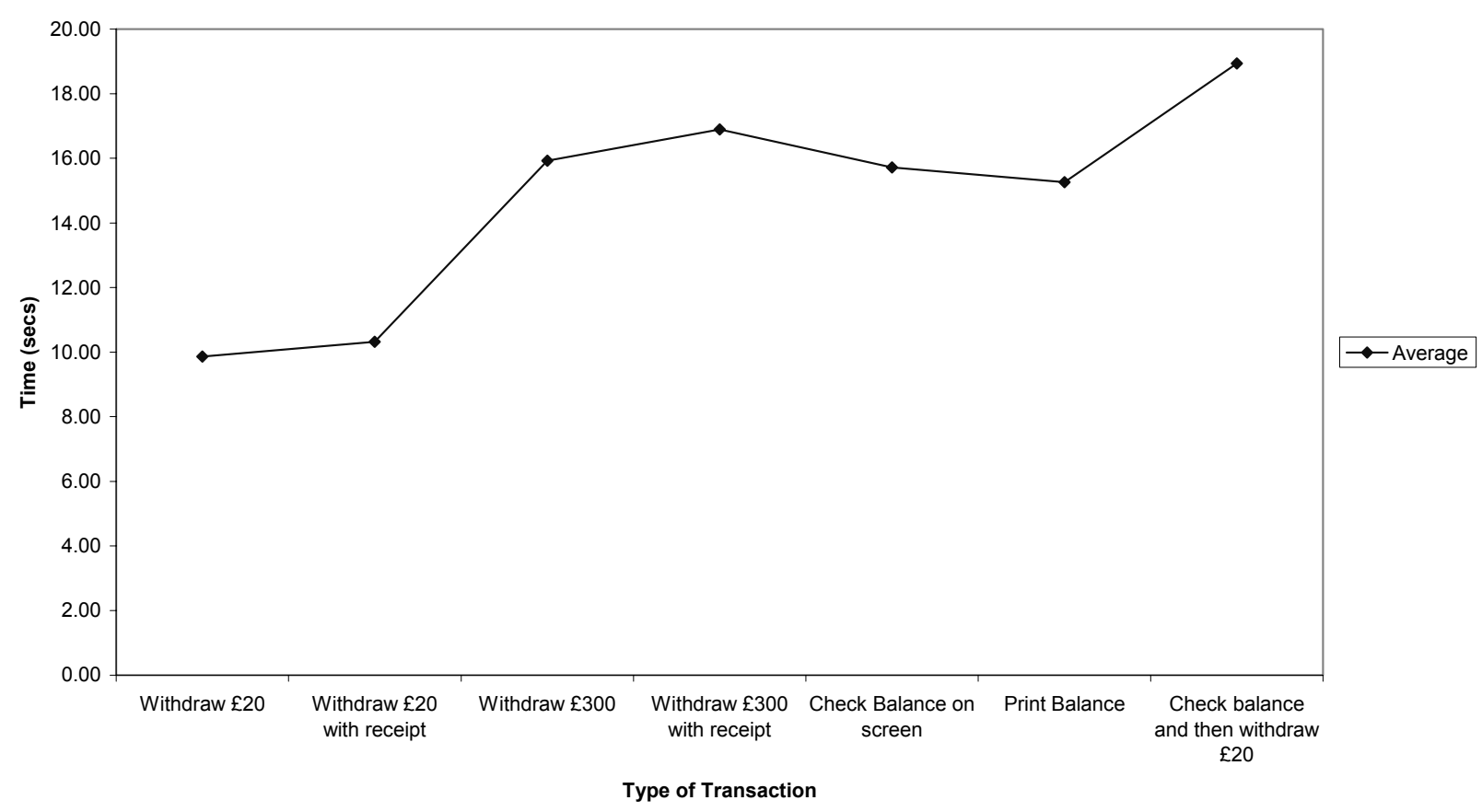

Figure 16. Bank of Ireland Transaction Performance Times

Time taken to withdraw $£ 20$

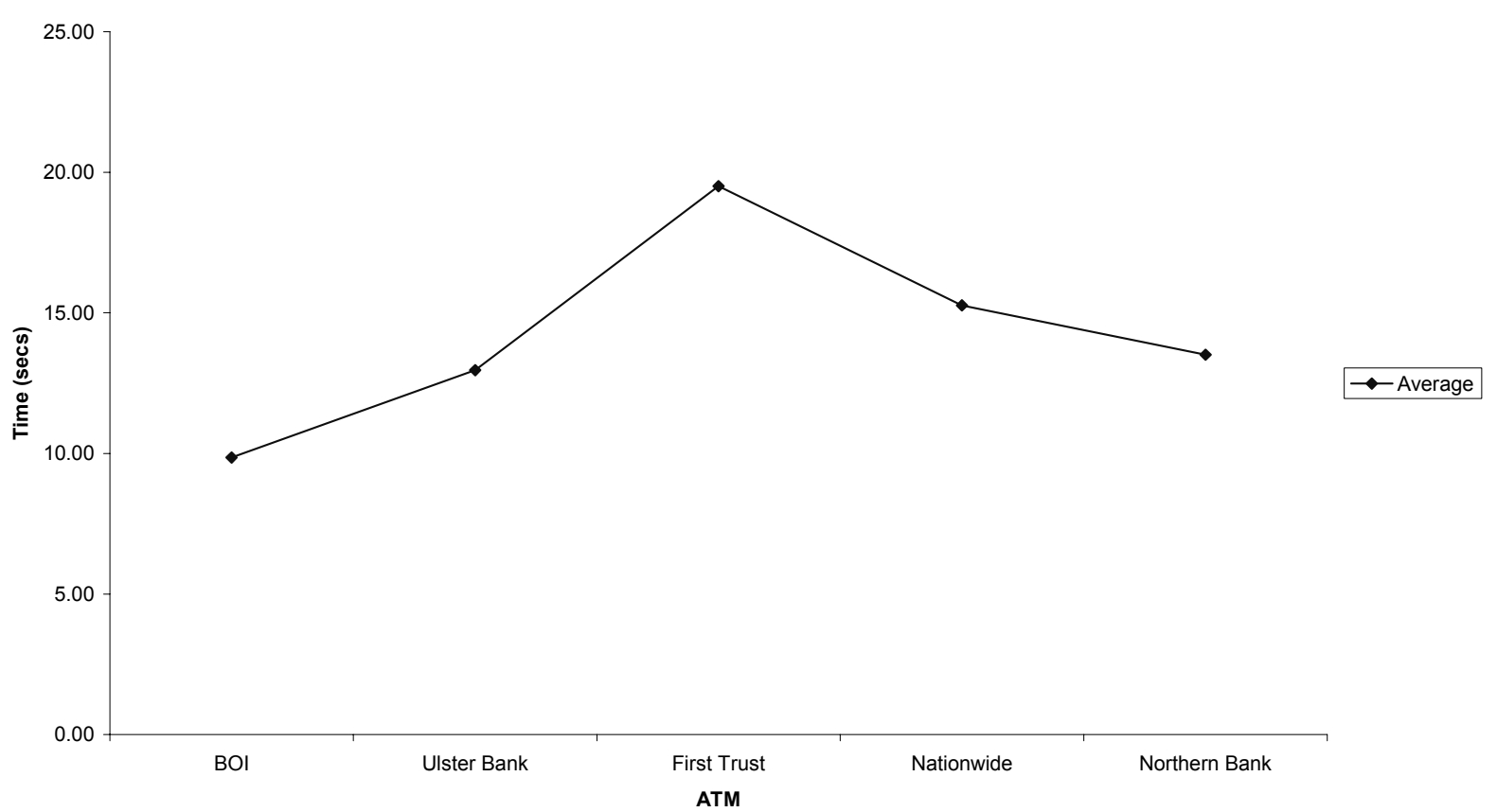

Figure 17. Times taken to withdraw $£ 20$ 


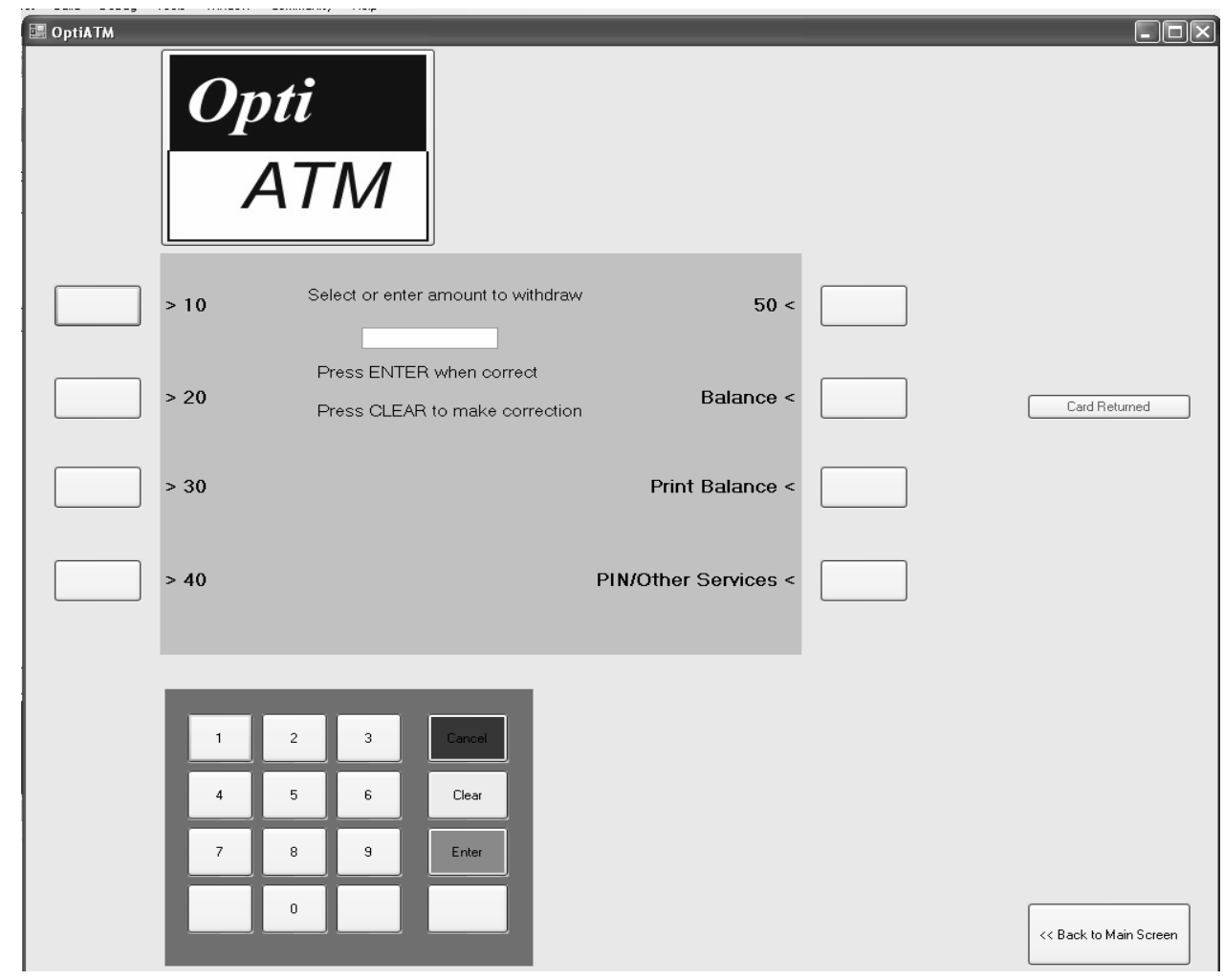

Figure 18. OptiATM User Options

Time taken to withdraw $£ 20$

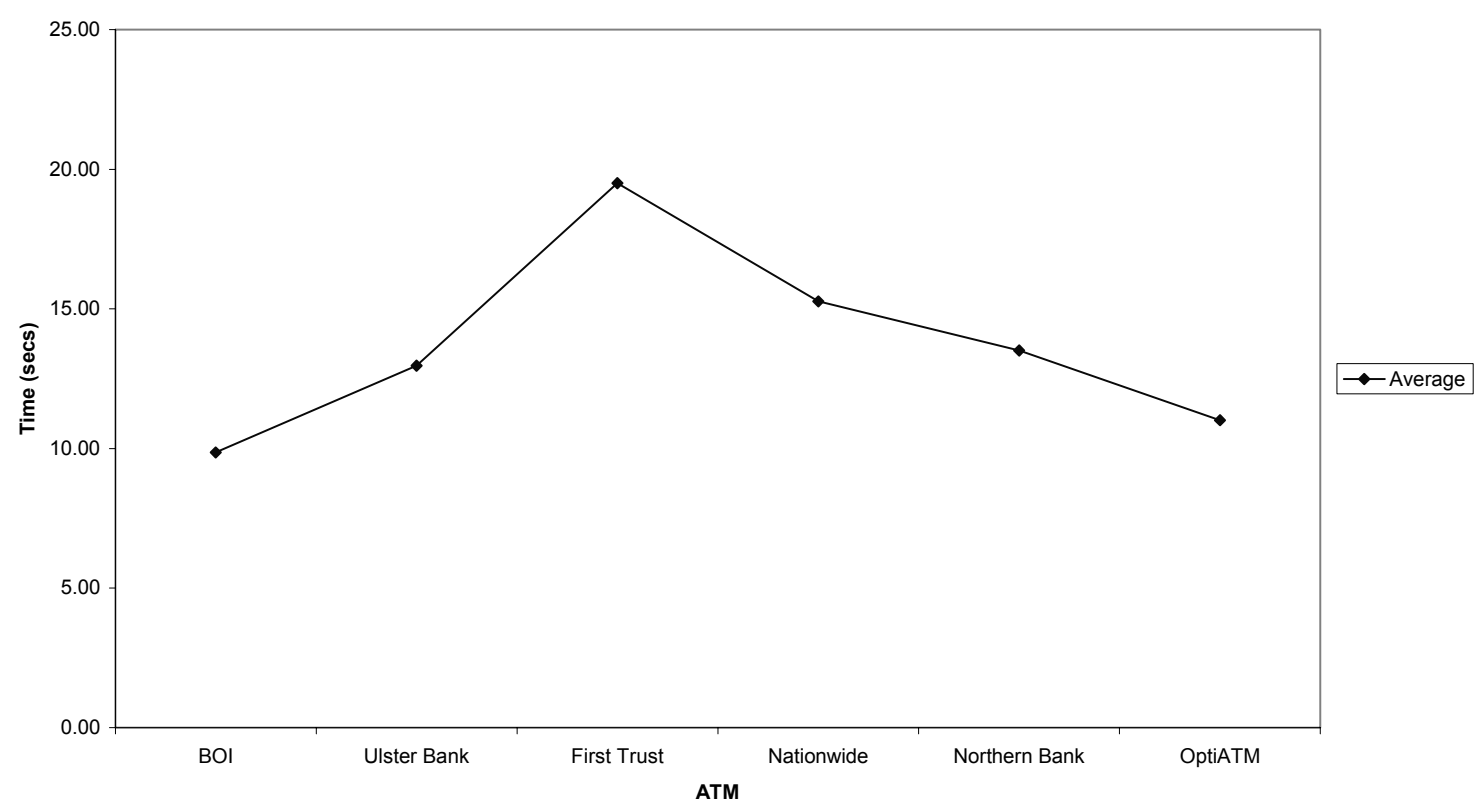

Figure 19. Comparing OptiATM - Withdraw $£ 20$ 


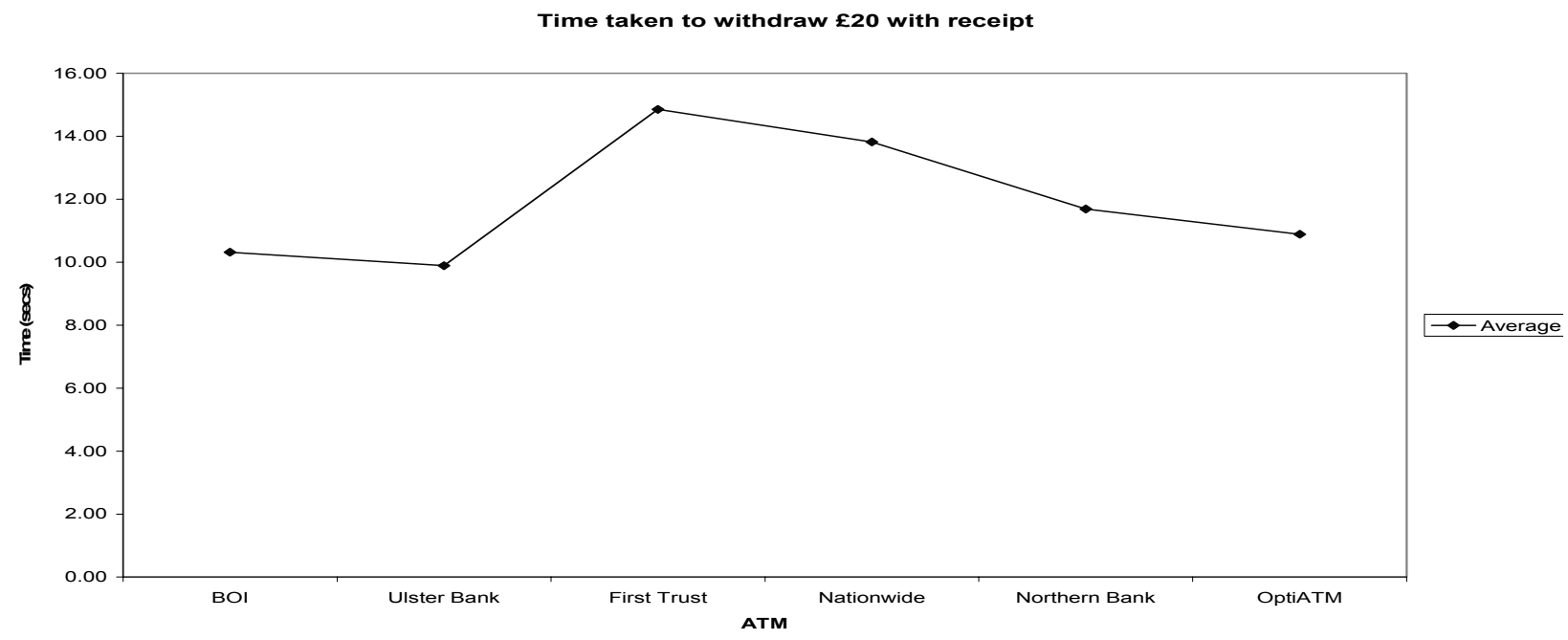

Figure 20. Comparing OptiATM - Withdraw $£ 20$ with receipt

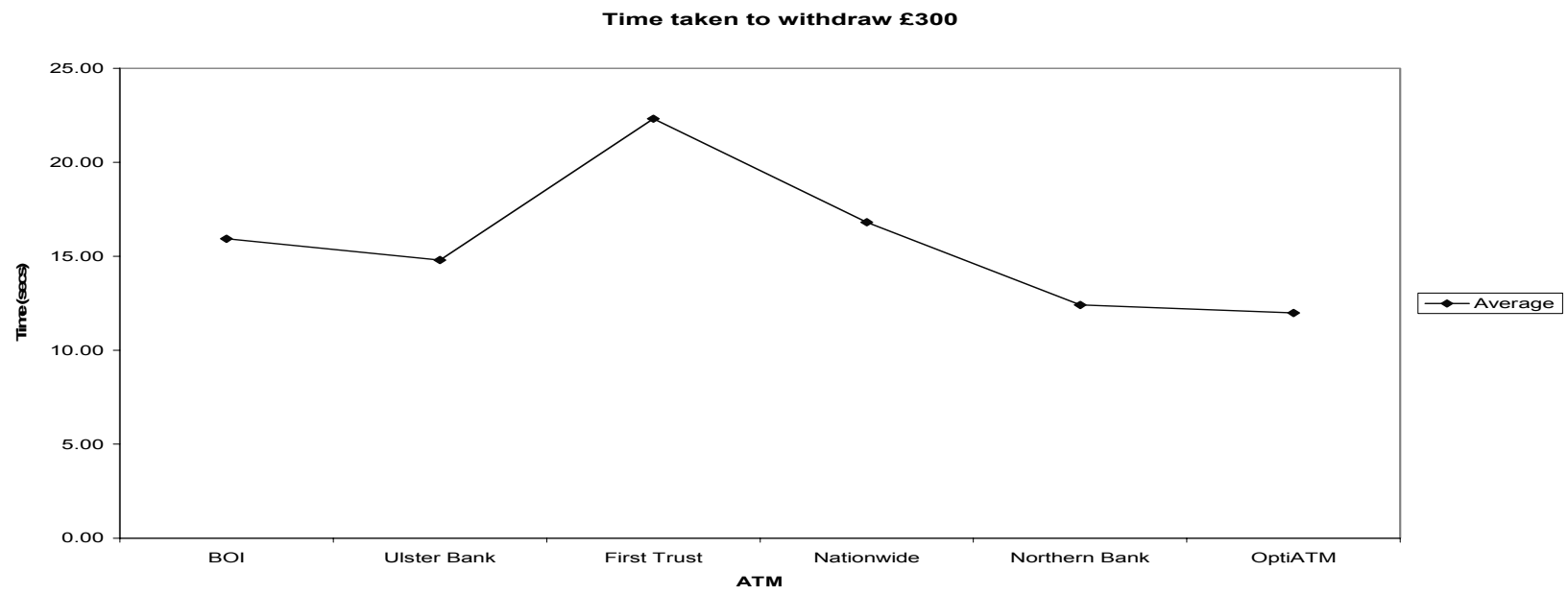

Figure 21. Comparing OptiATM - Withdraw $£ 300$ 
Time taken to check balance \& withdraw $£ 20$

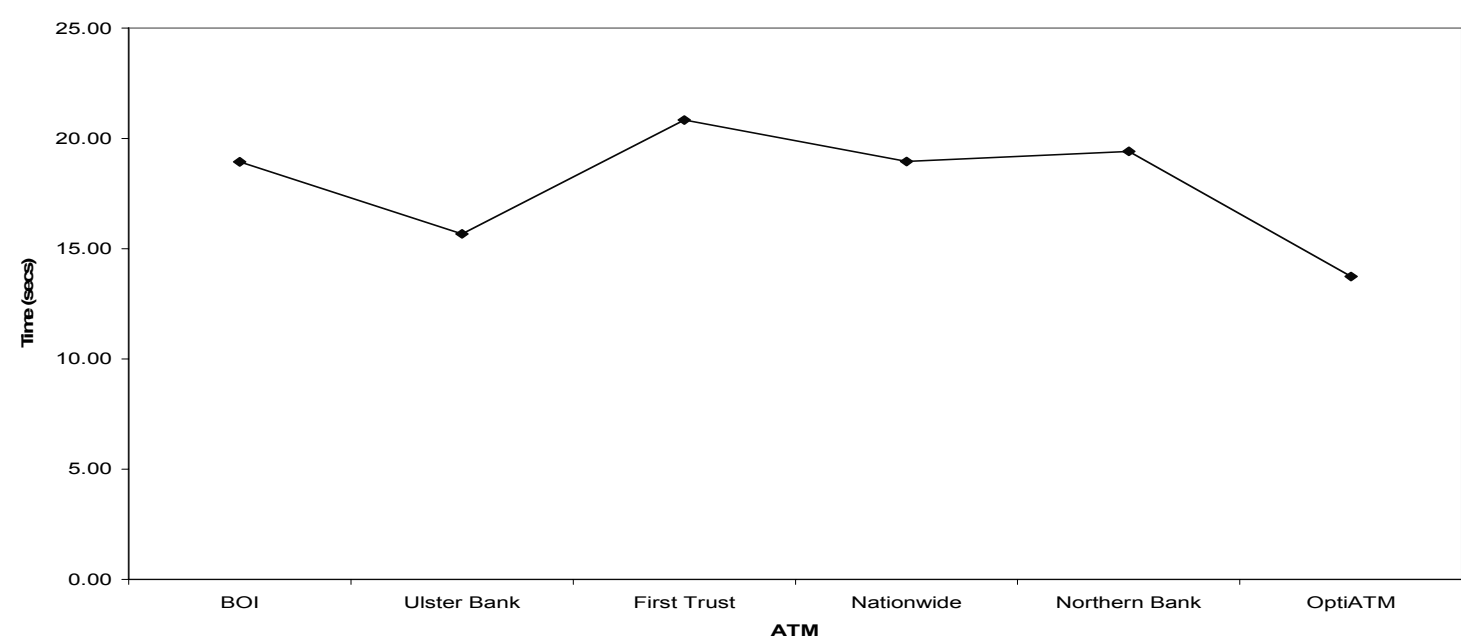

Figure 22. Comparing OptiATM - Check balance \& withdraw $£ 20$

Overall Performance Average

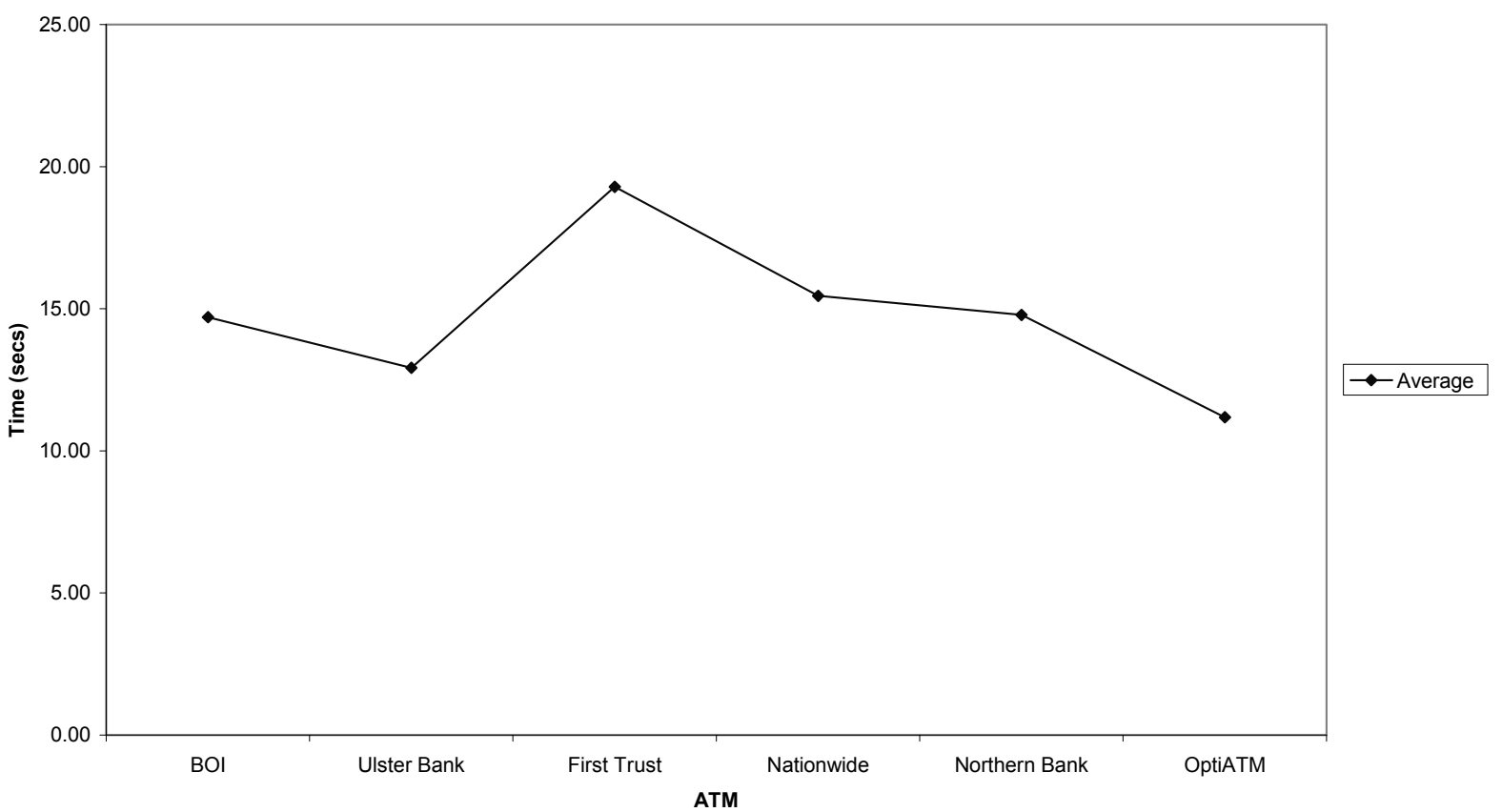

Figure 23. Average of overall transaction times for each ATM system 